\title{
AXIAL COMPRESSIVE BEHAVIOR OF SELF-STRESSING STEEL SLAG AGGRE- GATE CONCRETE FILLED STEEL TUBULAR COLUMNS WITH BOND-SLIP DAMAGE
}

\author{
Feng $\mathrm{Yu}^{1}$, Chi $\mathrm{Yao}^{1}$, Yi Hu ${ }^{2}$, Yuan Fang ${ }^{1,}{ }^{*}$, Kang Niu ${ }^{1}$ and Guo-sheng Xiang ${ }^{1}$ \\ ${ }^{1}$ Department of Civil Engineering and Architecture, Anhui University of Technology, Ma'anshan, China \\ ${ }^{2}$ China MCC 17 Group Co., Ltd, Ma'anshan, China \\ *(Corresponding author: Email:fyuan86@126.com)
}

\section{A B S T RA C T}

The axial compressive behavior of self-stressing steel slag aggregate concrete filled steel tubular (CFST) columns with bond-slip damage is investigated in this paper. Six bond-slip damaged specimens and two undamaged specimens with different diameter-thickness ratios and expansion ratios are tested. According to the test, the outward deformation dominates the failure of the axial loaded bond-slip damaged specimens. The ultimate bearing capacity is lower with higher diameter-thickness ratio, while the increase of the expansion ratio will bring benefits to bond-slip damaged specimens. The bond-slip damage has a little influence on the ultimate capacity. The ultimate displacement will be decreased by increasing the diameter-thickness ratio. The effect of expansion ratio on the longitudinal displacement is not obvious. The stiffness degradation can be mitigated by raising the expansion ratio. The ultimate axial and circumferential strains increase as the expansion ratio increases while they decease with the diameter-thickness ratio of bond-slip damaged specimens increasing. In addition, the accuracy of existing CFST design specifications for predicting the strength of bond-slip damaged specimens is evaluated.

\section{A R T I C L E H I S T O R Y}

\section{Received:}

Revised:

12 April 2019

Accepted: 06 September 2019

\section{K E Y W O R D S}

\section{CFST;}

Slag;

Expansion ratio;

Diameter-thickness ratio;

Ultimate bearing capacity

Stress-strain curve

\section{Introduction}

Steel slag produced from steel-making is one of the main types of solid waste. To date, a huge amount of steel slag has been discarded leading to a considerable land occupation and the pollution in air and water [1-2]. The Steel Slag Aggregate Concrete (SSAC), using the steel slag as the concrete aggregate, is proposed for recycling the industrial waste and preserving natural resources [3]. SSAC offers advantages such as low hydration heat, high strength and good durability [4-6]. However, the oxides, $\mathrm{MgO}$ and free- $\mathrm{CaO}$ in the steel slag might lead to micro-expansion of SSAC [7-10], which limits the application in civil engineering. To inhibit the volume instability, the self-stressing steel slag aggregate CFST column is proposed in this analysis.

CFST column utilizing the beneficial properties of concrete and steel has a high bearing capacity, good ductility and excellent seismic performance [11-14]. The bonding force significantly affect the mechanical properties of the composite member. Apparently, because of the volume shrinkage of the ordinary concrete during the curing, the bonding force would be decreased, and the slip defects would occur leading to the reduction of the bearing capacity, the safety and the durability of the structures [15-17].

By employing SSAC, the mechanical properties of the composite member could be effectively improved due to the slight expansion of SSAC. In recent years, Ferhoune [18] studied the behavior of the eccentrically loaded cold-formed steel tube with the crushed crystallized slag aggregate concrete and proved that the recycled slag could be integrated in the concrete manufacture. Zeghiche [19] parametrically investigated the influences of concrete strength and section geometry on the behavior of cold formed steel tube with crystallized slag aggregate concrete.

The investigations of defects mainly focused on the initial stress and eccentricities. Wei et. al. [20] revealed that the initial stress could significantly decrease the ultimate bearing capacity of single-set. Xiong et. al. [21] carried out a comprehensive numerical study on the mechanical behavior of CFST columns and discussed the influences of the eccentricity, length-thinness ratio, and initial stress ratio. Hu et. al. [22] conducted the experiments on the influences of the heat treatment and the arch rib deviation on the ultimate bearing capacity of steel tube arch. However, little research had been conducted on the member with the initial bond-slip imperfection.

In this study, Six bond-slip damaged specimens and two undamaged specimens under axial compression are tested. The effects of the diameter-thickness ratio and the expansion ratio on the mechanical behavior of bond-slip damaged specimens are detailed investigated. The influences of the bond-slip damage on the bearing capacity, longitudinal displacement, and stiffness of specimen are examined. Additionally, the bearing capacity of bond-slip damaged specimens is evaluated by the current CFST specifications.

\section{Experimental program}

\subsection{Specimen design}

In this analysis, eight self-stressing steel slag aggregate CFST columns including six bond-slip damaged specimens and two undamaged specimens, are designed and tested. The bond-slip damage is achieved through the push-out method from the undamaged column. The process includes three steps, namely (1) reserving $50 \mathrm{~mm}$ at the bottom of the specimens in the process of casting; (2) placing a circular steel plate slightly smaller than the inner diameter of the steel tube on the top of the core SSAC, and (3) loading the columns on the hydraulic compression testing machine until the specimen bond-slip fails (Fig. 1).
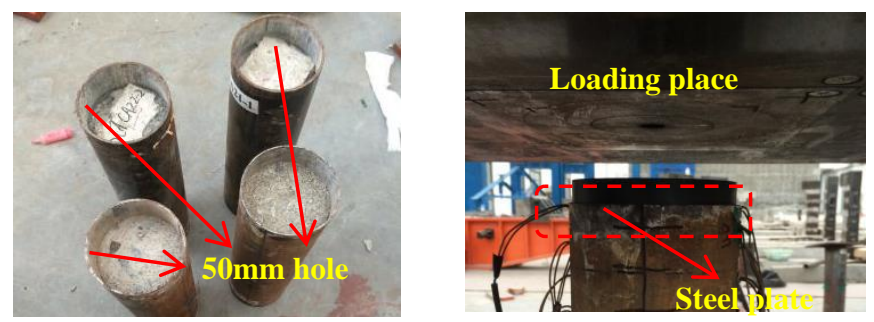

Fig. 1 The process of achieving bond-slip damage

The outer steel tube of specimens is made of Q235 steel. The tubes are 500 mm long with $140 \mathrm{~mm}$ outer diameter and $2.09 \mathrm{~mm}, 3.63 \mathrm{~mm}$ or $4.23 \mathrm{~mm}$ thickness. The pouring depths of SSAC are $450 \mathrm{~mm}$ and $500 \mathrm{~mm}$ in bond-slip damaged specimens and the undamaged specimens, respectively. Different diameter-thickness ratios (i.e., 33.10, 38.46, and 66.99), and expansion ratios (i.e., $2.8 \times 10-4$, and $-3.5 \times 10-4$ ) are adopted. More details are listed in Table 1.

\subsection{Material properties}

To investigate the influences of the expansion ratio on the mechanical behaviors of bond-slip damaged stub columns, two types of SSAC, such as the Ex-1 with the expansion ratio of $2.8 \times 10^{-4}$ and the Ex-2 with the expansion ratio of $-3.5 \times 10^{-4}$, are prepared, where the Ex-2 series is used to simulate the ordinary concrete. According to GB/T50082-2009 [23], the expansion ratio is determined by SSAC block test, as shown in in Fig. 2. The expansion ratio of SSAC can be calculated as:

$E_{\mathrm{x}}=\left(L_{\mathrm{t}}-L_{0}\right) / L_{\mathrm{e}}$ 
Where, $E_{\mathrm{x}}$ is the expansion ratio of SSAC on the $t$-day, $L_{\mathrm{e}}$ denotes the gauge length of the test block, $L_{0}$ represents the initial length of the test block on the third day, and $L_{\mathrm{t}}$ is the length of the test block after $\mathrm{t}$ days.

Table 1

Parameters of specimens

\begin{tabular}{cccccc}
\hline Specimen & $t_{\mathrm{s}} / \mathrm{mm}$ & $D / \mathrm{mm}$ & $D / t_{\mathrm{s}}$ & $E_{\mathrm{x}} / 10^{-4}$ & Type \\
\hline TCZY1-1 & 2.09 & 140 & 66.99 & 2.8 & \\
TCZY2-2 & & & & -3.5 & \\
TCZY3-1 & 3.64 & 140 & 38.46 & 2.8 & BSDS \\
TCZY4-2 & & & & -3.5 & \\
TCZY5-1 & 4.23 & 140 & 33.10 & 2.8 & \\
TCZY6-2 & & & & -3.5 & \\
ZY7-1 & 3.64 & 140 & 38.46 & 2.8 & Undamaged \\
ZY8-2 & & & & -3.5 & specimen \\
\hline
\end{tabular}

Note: $t_{\mathrm{s}}, D$ and $E_{\mathrm{x}}$ are the measured thickness, outside diameter of steel tube and expansion ratio of the SSAC, respectively. BSDS represents the bond-slip damaged specimen. (a) Schematic diagram of SSAC

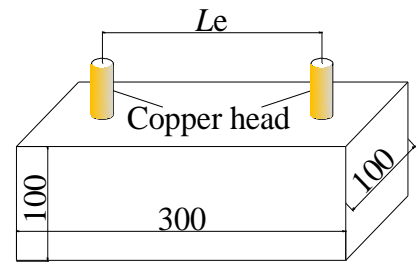

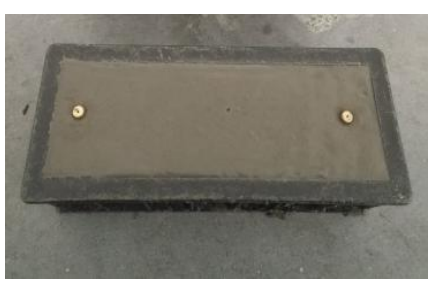

(b) Photo of the test block
Fig. 2 Test for measuring $E_{\mathrm{x}}$ of SSAC

According to "Metallic material - Tensile testing (GB/T228-2010)" Part I [24], the coupon test method is adopted to evaluate the mechanical properties of the steel tubes. The steel material properties are shown in Table 2. SSAC is made of graded gravel, steel slag (fine aggregate), P. O 42.5 cement, city tap water. The steel slag is continuously graded, and the particle size range of the steel slag is $0.15 \mathrm{~mm}$ to $2.36 \mathrm{~mm}$. The components of SSAC at different expansion ratios and the mechanical properties of SSAC are listed in Table 3.

\subsection{Test setup and procedure}

The experiments were conducted in the Structure and Earthquake Resistance Laboratory of Anhui University of Technology. A $5000 \mathrm{kN}$ hydraulic compression testing machine was employed for applying the monotonic static load, as shown in Fig.3. Two steel caps were prepared for both ends of speci- men. The axial and circumferential strain gauges (eight strain gauges) were evenly arranged at mid-height of columns, and two linear variable displacement transducers (LVDTs) were applied to measure the specimen's longitudinal deflections, as shown in Fig.3(a). Multi-stage loading was adopted in the experiments, and the initial load increment was $1 / 10$ of the estimated ultimate strength. When the specimens became inelastic, the load increment changed to $1 / 15$ of the estimated ultimate strength.

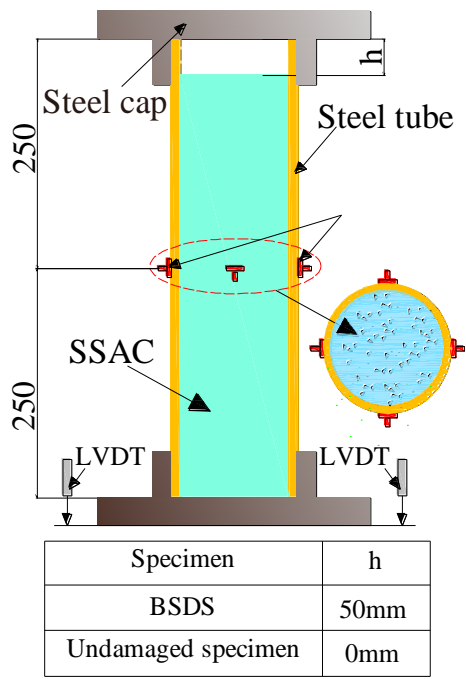

(a) Schematic diagram of specimens

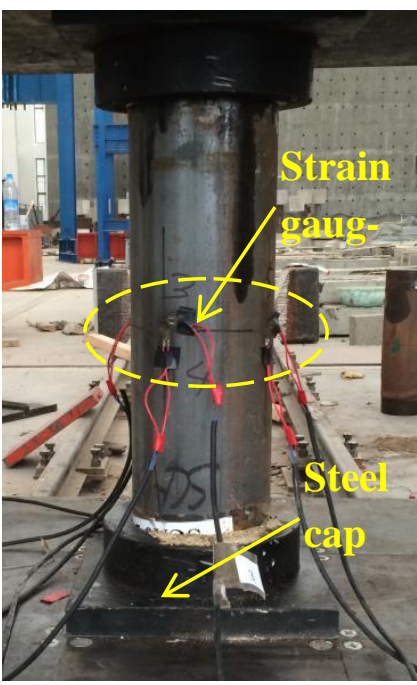

(b) Photo of the test setup
Note: BSDS represents the bond-slip damaged specimen.

Fig. 3 Test setup and measuring points arrangement

\section{Test procedure and failure modes}

Initially, the compressive load was mainly undertaken by the outer steel tube. As the load increased to $30 \%-45 \%$ of the ultimate strength, the local outward buckling appeared at the top of the steel tube. With the increase of load, the black rust on the surface of the outer steel tube gradually fell off, and the local outward buckling became obvious. The longitudinal deformation greatly increased while the compressive load approximately kept constant. As the load further increased, the top loading plate reached to SSAC. The outer steel tube and core SSAC carried load together. The stiffness of specimen increased significantly. As the load increased to $50 \%-60 \%$ of the ultimate strength, the slight noise of core SSAC cracking can be heard occasionally. When the load increased to $75 \%-85 \%$ of the ultimate strength, outward buckling appeared at middle of specimen, and large areas of black rust fell off. Cracks of core SSAC were frequently heard. Finally, specimens lost their bearing capacities and exhibited outward bucking failures as shown in Fig.4.

Table 2

Material properties of steel tube

\begin{tabular}{cccccc}
\hline Steel Grade & $\begin{array}{c}\text { Diameter } \\
/ \mathrm{mm}\end{array}$ & $\begin{array}{c}\text { Thickness } \\
/ \mathrm{mm}\end{array}$ & $\begin{array}{c}\text { Ultimate bearing } \\
\text { capacity /MPa }\end{array}$ & $\begin{array}{c}\text { Yield Strength } \\
/ \text { MPa }\end{array}$ & $\begin{array}{c}\text { Young's modulus } \\
\text { /MPa }\end{array}$ \\
\hline Q235 & 2.09 & 140 & 223 & 176 & $2.01 \times 10^{5}$ \\
Q235 & 3.64 & 140 & 296 & 233 & 0.301 \\
Q235 & 4.23 & 140 & 301 & 237 & Poisson's ratio \\
\hline
\end{tabular}

Table 3

The components of the two series of SSAC and mechanical properties

\begin{tabular}{|c|c|c|c|c|c|c|c|c|c|}
\hline \multirow{2}{*}{ Type } & \multirow{2}{*}{$\begin{array}{l}\text { Expansion } \\
\text { ratio } / 10^{-4}\end{array}$} & \multicolumn{4}{|c|}{ Material usage $/ \mathrm{kg} \cdot \mathrm{m}^{-3}$} & \multirow{2}{*}{$\begin{array}{l}\text { Particle size of } \\
\text { steel slag } / \mathrm{mm}\end{array}$} & \multirow{2}{*}{$\begin{array}{c}\text { Cube compressive } \\
\text { Strength /MPa }\end{array}$} & \multirow{2}{*}{$\begin{array}{c}\text { Young's modulus } \\
\text { /MPa }\end{array}$} & \multirow{2}{*}{ Poisson's ratio } \\
\hline & & Tap water & Cement & $\begin{array}{l}\text { Coarse } \\
\text { aggregate }\end{array}$ & Steel slag & & & & \\
\hline$E_{\mathrm{x}-1}$ & 2.8 & 202.1 & 366.1 & 962.1 & 622.1 & $\begin{array}{l}0.15 \sim 0.30(75 \%) \\
0.30 \sim 0.60(25 \%)\end{array}$ & 22.9 & $2.73 \times 10^{4}$ & 0.231 \\
\hline$E_{\mathrm{x}-2}$ & -3.5 & 202.1 & 366.1 & 962.1 & 622.1 & $1.18 \sim 2.36$ & 35.3 & $3.62 \times 10^{4}$ & 0.242 \\
\hline
\end{tabular}




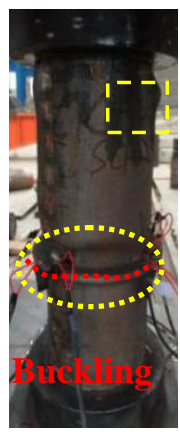

(a) TCZY2-1

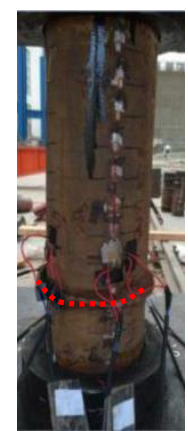

(b) TCZY2-2

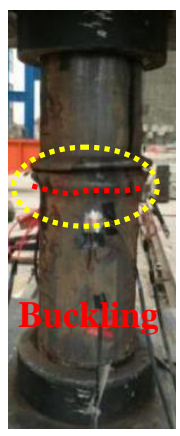

(c) TCZY3-1

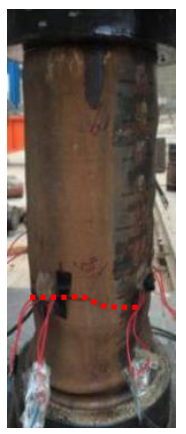

(d)TCZY4-2

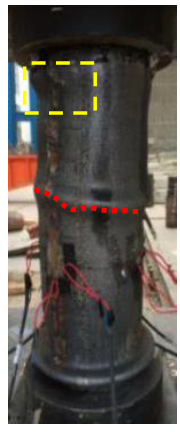

(e) TCZY5-1

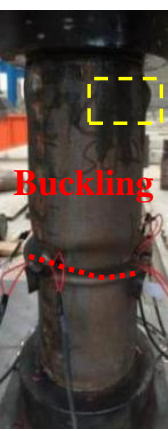

(f) TCZY6-2

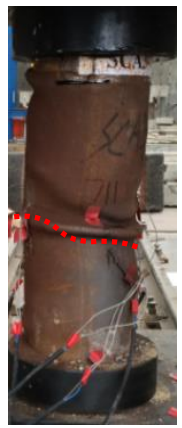

(g) ZY7-1

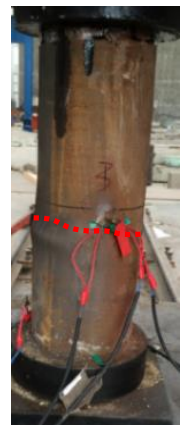

(h) ZY8-2

Fig. 4 Failure modes of specimens

\section{Experimental results and analysis}

\subsection{Bearing capacity}

The ultimate bearing capacity of bond-slip damaged specimens with different diameter-thickness ratios is depicted in Fig.5. Apparently, the increase in the diameter-thickness ratio of bond-slip damaged specimens decreases the ultimate bearing capacity. For the columns with $-3.5 \times 10^{-4}$ expansion ratio, the ultimate bearing capacity of bond-slip damaged specimens with the diameter-thickness ratio 66.99 is $39 \%$ lower than the bond-slip damaged specimens with the diameter-thickness ratio 33.10. This is mainly because the confinement effect decreases as the diameter-thickness ratio of bond-slip damaged specimens increases.

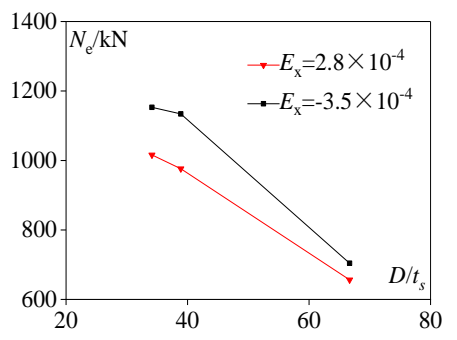

Fig. 5 Effect of $D / t_{\mathrm{s}}$ on bearing capacity

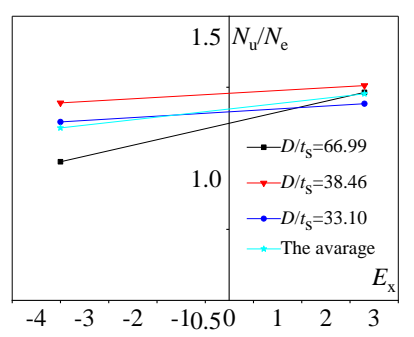

Fig. 6 Effect of $E_{\mathrm{x}}$ on $N_{\mathrm{u}} / N_{\mathrm{e}}$
The Incremental Range of the Ultimate Bearing Capacity $\left(N_{\mathrm{u}} / N_{\mathrm{e}}\right)$, the ratio between the ultimate bearing capacity $\left(N_{\mathrm{u}}\right)$ and the nominal compressive strength $\left(N_{\mathrm{e}}=f_{\mathrm{y}} A_{\mathrm{s}}+f_{\mathrm{c}} A_{\mathrm{c}}\right)$, is adopted to evaluate the influence of the expansion ratio on the ultimate bearing capacity of bond-slip damaged specimens, as showed in Fig.6. $N_{\mathrm{u}} / N_{\mathrm{e}}$ increases as the expansion ratio of bond-slip damaged specimens increases. The average $N_{\mathrm{u}} / N_{\mathrm{e}}$ of bond-slip damaged specimens with expansion ratio of $-3.5 \times 10^{-4}$ is $11.8 \%$ lower than the bond-slip damaged specimens with the expansion ratio of $2.8 \times 10^{-4}$. Take the bond-slip damaged specimens with the diameter-thickness ratio of 66.99 as an example, when the expansion ratio increases from $-3.5 \times 10^{-4}$ to $2.8 \times 10^{-4}, N_{\mathrm{u}} / N_{\mathrm{e}}$ of bond-slip damaged specimens increases by $24.7 \%$. Therefore, the decrease of the diameter-thickness ratio or the increase of the SSAC expansion ratio in a reasonable range can effectively improve the ultimate bearing capacity.

Specimens TCZY4-2 and ZY8-2 are employed to reveal the effect of bond-slip damage on the bearing capacity. The load-deflection curves of the specimens are plotted in Fig.7. Obviously, the undamaged specimen exhibits three stages, namely, the elastic stage, the elastoplastic stage and the plastic stage. For bond-slip damaged specimens, an additional strengthening stage is appeared within the second and third stages. The proportion limit of the undamaged specimen is $809.6 \mathrm{kN}$, which is 4.05 times than that of the bond-slip damaged specimen. This may be due to the different mechanic performances The axial load of bond-slip damaged specimens is only carried by the steel tube, while the axial load of undamaged specimen is carried by both the core SSAC and steel tube. As the load increases, the specimen enters the second stage. The difference between the undamaged specimen and bond-slip damaged specimens is obvious in this stage. The yield strength of undamaged specimen and bond-slip damaged specimens are $936.2 \mathrm{kN}$ and $300.1 \mathrm{kN}$ respectively. After that, the bearing capacity of bond-slip damaged specimens increases significantly, while that of undamaged specimen does not. Finally, the ultimate bearing capacity of undamaged specimen and bond-slip damaged specimens are approximate consistent. The bond-slip damage has a little influence on the ultimate strength, while the bond-slip damage has a remarkable influence on yield strength. The detailed experimental results of specimens on bearing capacity and displacement are shown in Table 4 .

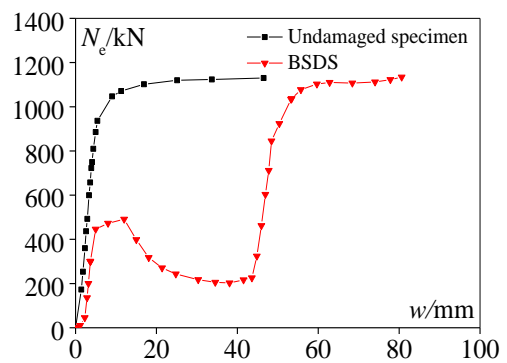

Fig. 7 Effect of bond-slip damage on bearing capacity

Table 4

Experimental results of specimens on bearing capacity and displacement

\begin{tabular}{|c|c|c|c|c|c|c|}
\hline Specimen & Proportion limit/kN & Elastic displacement $/ \mathrm{mm}$ & Yield load/kN & Yield displacement/mm & Ultimate load/kN & Ultimate displacement/mm \\
\hline TCZY1-1 & 143.2 & 0.8 & 251.8 & 3.0 & 656.0 & 60.0 \\
\hline TCZY2-2 & 147.7 & 0.9 & 252.7 & 3.1 & 704.0 & 60.0 \\
\hline TCZY3-1 & 202.5 & 3.1 & 298.6 & 3.6 & 976.2 & 79.0 \\
\hline TCZY4-2 & 200.1 & 3.2 & 300.1 & 3.7 & 1134.0 & 80.6 \\
\hline TCZY5-1 & 318.4 & 1.3 & 490.2 & 2.5 & 1016.0 & 82.1 \\
\hline TCZY6-2 & 329.8 & 1.4 & 487.7 & 2.4 & 1153.0 & 83.3 \\
\hline ZY7-1 & 736.3 & 4.3 & 832.2 & 5.3 & 979.3 & 45.4 \\
\hline ZY8-2 & 809.6 & 4.4 & 936.2 & 5.4 & 1130.2 & 46.5 \\
\hline
\end{tabular}




\subsection{Load-displacement}

The effects of the expansion ratio and the diameter-thickness ratio on the load-displacement relationship are depicted in Fig.8. Initially, the load-displacement relationship is approximate linear. As the load increases, the load-displacement curve deviates from the linearity. The axial load decreases slightly while the longitudinal displacement of bond-slip damaged specimens increases greatly. Outward buckling appears at mid-height of the steel tube and the longitudinal displacement of specimen quickly approach to $50 \mathrm{~mm}$. As the axial load increases further, the bond-slip damaged specimen enters the hardening range. Finally, the outward deformation dominates the failure of the bond-slip damaged specimens, and the overall deformation is large.

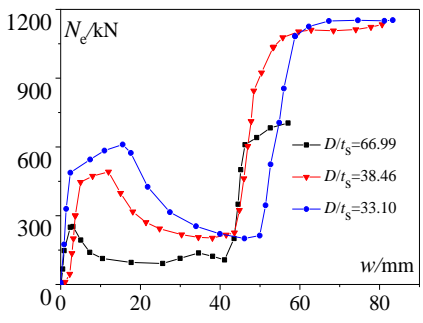

(a) $E_{\mathrm{x}}=-3.5 \times 10^{-4}$

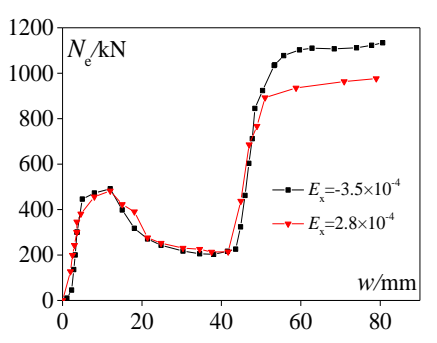

(b) $D / t_{\mathrm{s}}=38.46$
Fig. 8 Effect of two studied parameters on load-displacement relationship of BSDS

The increase of the diameter-thickness ratio would decrease the longitudinal displacement of bond-slip damaged specimens, as shown in Fig.8(a). This may come from that the confinement effect of steel tube on core SSAC decreases as the diameter-thickness ratio increases, and core SSAC is more susceptible to outward failure, leading to the decrease of ultimate deformation.

The load-displacement relationship curves of bond-slip damaged specimens with different expansion ratios are presented four stages, as shown in Fig.8(b). The effect of expansion ratio on the longitudinal displacement of bond-slip damaged specimens is not obvious.

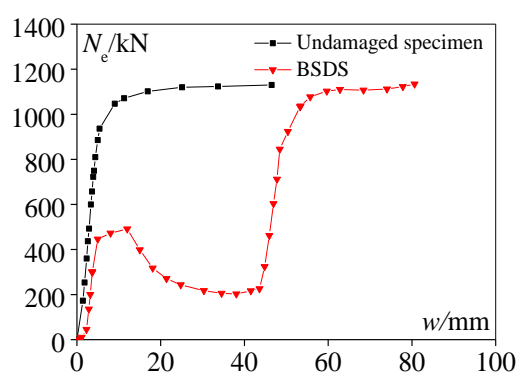

Fig. 9 Effect of bond-slip damage on load-displacement curves

Take specimens TCZY4-2 and ZY8-2 as example, the effect of bond-slip damage on load-displacement curves is depicted in Fig.9. Compared with undamaged specimen, the slope of the bond-slip damaged specimens in the elastic stage is smaller, and the longitudinal displacement of bond-slip damaged specimens in the elastoplastic stage is remarkable. These indicate that the bond force can significantly reduce the longitudinal displacement of the specimen. A hardening range is appeared in the load-displacement curve of bond-slip damaged specimens, and the curve is approximate linear in this stage. When the bond-slip damaged specimens and undamaged specimen are close to failure, the load-displacement relationship curves finally show a horizontal section. Obviously, the ultimate deformation of bond-slip damaged specimens is larger than that of the undamaged specimen.

\subsection{Stiffness}

Fig.10. depicts the relationship between the stiffness ( $\left.K_{\mathrm{a}}\right)$ and load $\left(N_{\mathrm{a}}\right)$ of bond-slip damaged specimens. The load-stiffness curve of bond-slip damaged specimens roughly divides into four parts. The first stage is the horizontal part, and the stiffness of the bond-slip damaged specimens changes little. In this part, only the outer steel tube carried the axial load, and the bond-slip damaged specimens is in the elastic stage. As the load increases, the bond-slip damaged specimens enters the second stage (the descending part). With the yielding of steel tube, the stiffness of bond-slip damaged specimens degenerates rapidly. When the loading plate reaches to SSAC, the bond-slip damaged specimens enters the third stage (the recovery part). The outer steel tube and core SSAC begin to carry the load together, and the composite stiffness of bond-slip damaged specimens increases. As the load further increases, the bond-slip damaged specimens enters the last stage (the second descending part), and the stiffness of bond-slip damaged specimens drops sharply.

As the confinement effect of the outer tube is inadequate due to the increase of the diameter-thickness ratio, a high diameter-thickness ratio would decrease the stiffness of the bond-slip damaged specimens, shorten the recovery part of load-stiffness curve and aggravate the stiffness degradation.

Fig.11. shows the effect of expansion ratio on the stiffness of bond-slip damaged specimens. In the horizontal part and the descending part, the influence of the expansion ratio on the load-stiffness curve of bond-slip damaged specimens is not significant. The axial stiffness is mainly related to the steel tube. The bond-slip damaged specimens with a higher expansion ratio has a longer recovery part, a shorter second descending part with a rapid stiffness degradation. This may come from that the premature development of SSAC micro-cracks can be confined effectively by the outer steel tube. However, the development of SSAC micro-cracks couldn't be confined by the yielding steel tube at the later loading stage, and the core SSAC with a higher expansion ratio is more likely to crush without the effective constraint of outer steel tube.

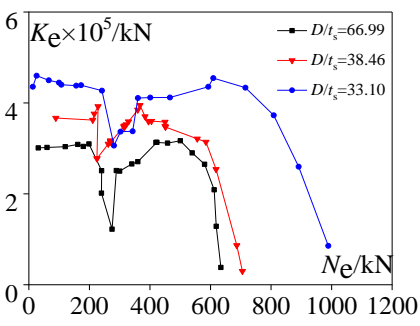

Fig. 10 Effect of $D / t_{\mathrm{s}}$ on stiffness

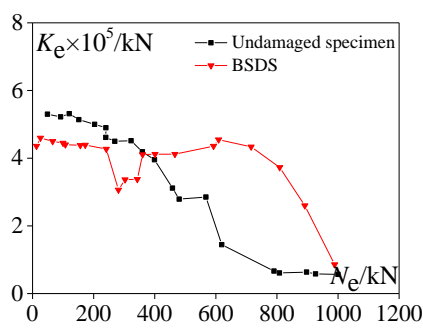

Fig. 11 Effect of $E_{x}$ on stiffness
Specimens TCZY4-2 and ZY8-2 are employed to investigate the effect of bond-slip damage on load-stiffness curves, as shown in Fig.12. Compared with the bond-slip damaged specimens, the early stiffness of undamaged specimen is larger, this is mainly because the early stiffness of undamaged specimen is the combined stiffness, while the early stiffness of bond-slip damaged specimens is approximate equal to that of the outer steel tube. When the loading plate reaches to SSAC, the stiffness of bond-slip damaged specimens increases. As the load further increases, the load-stiffness curves of bond-slip damaged specimens and undamaged specimen tend to overlap.

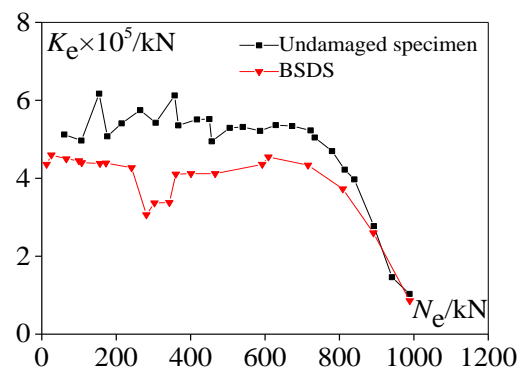

Fig. 12 Effect of bond-slip damage on load-stiffness curves

\subsection{Stress-strain}

The effects of expansion ratio and diameter-thickness on stress-strain relationship of bond-slip damaged specimens are depicted in Fig.13. - Fig.16, where $\varepsilon_{\text {ea }}, \varepsilon_{\text {el } 1}$ are the measured circumferential strain and axial strain at middle height of specimen.

The expansion ratio has a little influence on the bond-slip damaged specimens in the elastic and elastoplastic stages. The stress-strain curves of bond-slip damaged specimens with two expansion ratios are approximate consistent in these two stages. However, the bond-slip damaged specimens with higher SSAC expansion ratio has a larger slope in the hardening stage, as shown in Fig.13. This is mainly because the premature development of the SSAC micro-cracks can be confined effectively by the steel tube, and the early stiffness degeneration ratio is low with higher expansion ratio. The ultimate axial and circumferential strains increase as the expansion ratio increase, while the influence of the expansion ratio on the circumferential strain is more obvious, as shown in Fig.14. For example, the ultimate axial and circumferential strains of the specimen with diameter-thickness ratio of 38.46 increase by $16.9 \%$ and $4.5 \%$ respectively, when increasing the expansion ratio from $-3.5 \times 10^{-4}$ to $2.8 \times 10^{-4}$. 


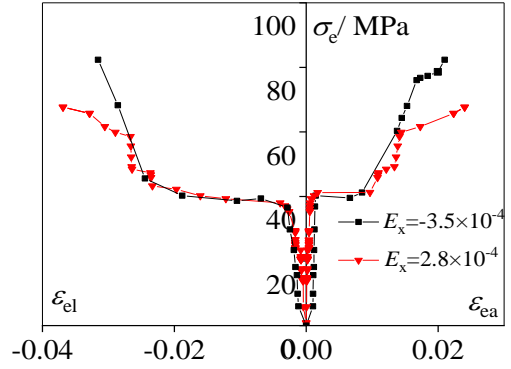

Fig. 13 Effect of $E_{\mathrm{x}}$ on stress-strain relationship

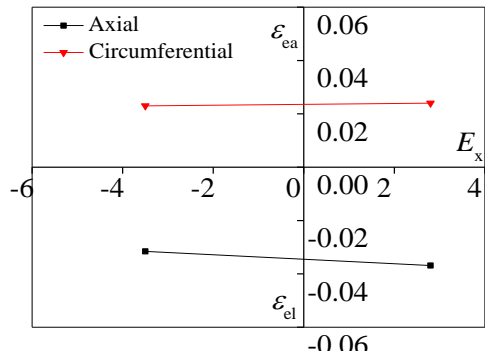

Fig. 14 Effect of $E_{x}$ on ultimate strain

The influence of diameter-thickness ratio on the stress-strain relationship is not obvious in the first and second stages. In the hardening stage, the slope of bond-slip damaged specimens decreases as the diameter-thickness ratio increases, as shown in Fig.15. This may come from that the increase in the diameter-thickness ratio decreases the composite stiffness of bond-slip damaged specimens in the hardening stage.

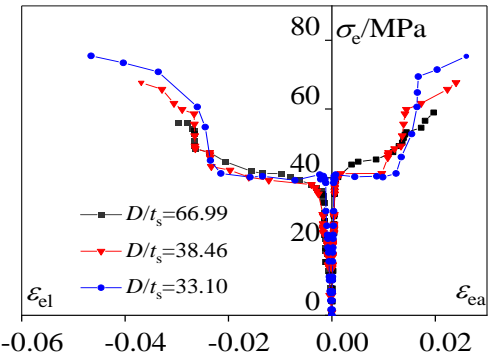

Fig. 15. Effect of $D / t_{\mathrm{s}}$ on stress-strain relationship

The ultimate axial and circumferential strains decrease as the diameter-thickness ratio of bond-slip damaged specimens increases, as shown in Fig.16. This is mainly because the confinement effect of outer steel tube on core SSAC decreases as the diameter-thickness ratio increases, and outward bucking failure of core SSAC is more likely to occur, leading to the decrease of ultimate strains.

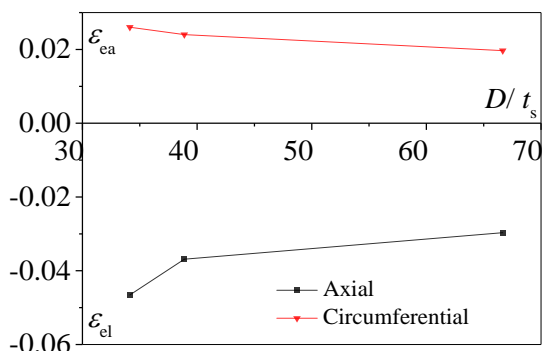

Fig. 16 Effect of $D / t_{\mathrm{s}}$ on ultimate strain

Fig.17. depicts the stress-strain relationship of specimens TCZY4-2 and ZY8-2. Compared with the undamaged specimen, an additional hardening stage is appeared in the stress-strain relationship curve of bond-slip damaged specimens. The ultimate axial and circumferential strains of the bond-slip damaged specimens are obvious greater than those of the undamaged specimens. However, the ultimate stress of bond-slip damaged specimens is approximate consistent with that of the undamaged specimens.

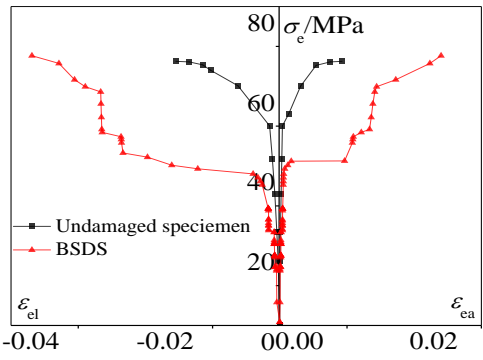

Fig. 17 Effect of bond-slip damage on stress-strain curves

\section{Design recommendations}

In this part, the applicability of the current CFST design methods for predicting the bearing capacity of bond-slip damaged specimens is examined The ultimate bearing capacity of bond-slip damaged specimens estimated by GB50936-2014, AIJ-CFT (1997), ANSI/AISC360-16 (2016), and Eurocode 4 (2004) are compared to the test data.

\subsection{Chinese code GB50936-2014[25]}

On the basis of a large number of experimental and analytical investigations, the unified theory is adopted for predicting the strength of CFST members under axial compression in Chinese code GB50936-2014. The formula is as follow.

$N \leq N_{\mathrm{u}}=f_{\mathrm{sc}} A_{\mathrm{sc}}$

$f_{\mathrm{sc}}=\left(1.212+B \theta+C \theta^{2}\right) f_{\mathrm{c}}$

$B=0.176 f_{\mathrm{y}} / 213+0.974$

$C=-0.104 f_{c} / 14.4+0.031$

where $f_{\text {sc }}$ represents the design value of compressive strength of CFST member, $A_{\mathrm{sc}}$ denotes the section area of CFST member, $B, C$ are the calculated coefficient, which are fitted by a large number of experimental results, $\theta$ is the confinement index, $\theta=f_{\mathrm{y}} A_{\mathrm{s}} / f_{\mathrm{c}} A_{\mathrm{c}}$.

\subsection{Japan code AIJ-CFT (1997) [26]}

In Japan code AIJ-CFT, the axial strength of CFST member is calculated by proportionally combining the bearing capacity of internal concrete and external steel tube. The formula for predicting the strength of CFST under axial load is as follow.

$N=1.27 A_{\mathrm{s}} F+k f_{\mathrm{cd}} A_{\mathrm{c}}$

$F=\min \left(f_{\mathrm{y}}, 0.7 f_{\mathrm{u}}\right)$

in which, $F$ is the characteristic value of strength of steel tube, $f_{\mathrm{u}}$ is the ultimate bearing capacity of steel tube, $k$ is the reduction coefficient of compressive strength of concrete cylinder, and $k=0.85$.

\subsection{American specification - ANSI/AISC 360-16 (2016) [27]}

The specification evaluates the overall stability of composite members through the conventional stability design equation as provided in Eq. (8). The contribution of the inner concrete is converted into the nominal compressive strength of steel given in Eq. (9). The strength of CFST members could be designed according to pure steel components.

$N=\varphi_{\mathrm{c}} P_{\mathrm{n}}$

$\begin{cases}P_{\mathrm{n}}=P_{\mathrm{no}} 0.658^{P_{\mathrm{no}} / P_{\mathrm{e}}} & P_{\mathrm{no}} / P_{\mathrm{e}} \leq 2.25 \\ P_{\mathrm{n}}=0.877 P_{\mathrm{e}} & P_{\mathrm{no}} / P_{\mathrm{e}} \geq 2.25\end{cases}$

in which, $N$ denotes the design value of axial compression column, $P_{\mathrm{n}}$ is nominal axial strength; $\varphi_{\mathrm{c}}=0.75 ; P_{\mathrm{no}}=f_{\mathrm{y}} A_{\mathrm{s}}+0.85 f_{\mathrm{cd}} A_{\mathrm{c}}+f_{\mathrm{ys}} A_{\mathrm{sr}} ; f_{\mathrm{ysr}}$ and $f_{\mathrm{y}}$ are the specified yield stress of reinforcing bars and steel section, respectively; $f_{\text {cd }}$ is the specified concrete compressive strength; $A_{\mathrm{c}}, A_{\mathrm{s}}$, and $A_{\mathrm{sr}}$ were the cross-sectional area of steel, concrete, and reinforcing bars, respective- 
ly; $P_{\mathrm{e}}$ represents the elastic critical buckling load, $P_{\mathrm{e}}=\pi^{2}\left(E I_{\mathrm{eff}}\right) /(K L)^{2} ; K$ is the effective length factor; $L$ is the laterally unbraced length of the member; $E I_{\text {eff }}=E_{\mathrm{s}} I_{\mathrm{s}}+0.5 E_{\mathrm{s}} I_{\mathrm{sr}}+C_{1} E_{\mathrm{c}} I_{\mathrm{c}} ; \quad E I_{\text {eff }}$ is the section effective bending stiffness; $E_{\mathrm{c}}$ and $E_{\mathrm{s}}$ are Young's modulus of concrete and steel, respec- tively; $I_{\mathrm{c}}, I_{\mathrm{s}}$ and $I_{\mathrm{sr}}$ are the moment of inertia of concrete, steel tube, and reinforcing bars about the section elastic neutral axis, respectively; $C_{1}=0.1+2 A_{\mathrm{s}} /\left(A_{\mathrm{c}}+A_{\mathrm{s}}\right) \leq 0.3$.

Table 5

Contrast between theoretical calculated and experimental results of columns

\begin{tabular}{|c|c|c|c|c|c|c|c|c|c|}
\hline \multirow{2}{*}{ Specimen number } & \multirow{2}{*}{$\begin{array}{c}\text { Experimental data } \\
N_{\mathrm{u}} \\
/ \mathrm{kN}\end{array}$} & \multicolumn{2}{|c|}{ GB50936-2014 } & \multicolumn{2}{|c|}{ AIJ -CFT (1997) } & \multicolumn{2}{|c|}{ ANSI/AISC 360-16 (2016) } & \multicolumn{2}{|c|}{ Eurocode 4 (2004) } \\
\hline & & $\begin{array}{l}N_{\mathrm{c} 1} \\
/ \mathrm{kN}\end{array}$ & $\frac{N_{\mathrm{u}}}{N_{\mathrm{c} 1}}$ & $\begin{array}{l}N_{\mathrm{c} 2} \\
/ \mathrm{kN}\end{array}$ & $\frac{N_{\mathrm{u}}}{N_{\mathrm{c} 2}}$ & $\begin{array}{l}N_{\mathrm{c} 3} \\
/ \mathrm{kN}\end{array}$ & $\frac{N_{\mathrm{u}}}{N_{\mathrm{c} 3}}$ & $\begin{array}{l}N_{\mathrm{c} 4} \\
/ \mathrm{kN}\end{array}$ & $\frac{N_{\mathrm{u}}}{N_{\mathrm{c} 4}}$ \\
\hline TCZY1-1 & 656 & 525 & 1.25 & 439 & 1.49 & 319 & 2.06 & 573 & 1.15 \\
\hline TCZY2-2 & 704 & 709 & 0.99 & 583 & 1.21 & 425 & 1.66 & 742 & 0.95 \\
\hline TCZY3-1 & 976 & 758 & 1.29 & 610 & 1.60 & 462 & 2.11 & 876 & 1.11 \\
\hline TCZY4-2 & 1134 & 937 & 1.21 & 747 & 1.52 & 563 & 2.01 & 1038 & 1.09 \\
\hline TCZY5-1 & 1016 & 827 & 1.23 & 731 & 1.39 & 506 & 2.01 & 967 & 1.05 \\
\hline TCZY6-2 & 1153 & 1003 & 1.15 & 866 & 1.33 & 606 & 1.90 & 1126 & 1.02 \\
\hline \multicolumn{2}{|c|}{ Mean of $N_{\mathrm{u}} / N_{\mathrm{e}}$} & \multicolumn{2}{|c|}{1.1866} & \multicolumn{2}{|c|}{1.4235} & \multicolumn{2}{|c|}{1.9589} & \multicolumn{2}{|c|}{1.0627} \\
\hline \multicolumn{2}{|c|}{ Mean square error of $N_{\mathrm{u}} / N_{\mathrm{e}}$} & \multicolumn{2}{|c|}{0.0092} & \multicolumn{2}{|c|}{0.0170} & \multicolumn{2}{|c|}{0.0222} & \multicolumn{2}{|c|}{0.0042} \\
\hline
\end{tabular}

Note: $N_{\mathrm{u}}$ denotes the experimental ultimate bearing capacity, $N_{\mathrm{c}}$ stand for the calculation result according to various specifications.

\subsection{European specification - Eurocode 4 (2004) [28]}

In European specification - Eurocode 4, the full section of specimen coming into plasticity is assumed for estimating the strength of CFST members under axial load. That is, when the axially loaded CFST members reaches the ultimate strength, the outer steel tube and the concrete core reach their ultimate compressive bearing capacity, simultaneously.

$N \leq \chi N_{\mathrm{u}}$

$N_{\mathrm{u}}=\eta_{\mathrm{ao}} f_{\mathrm{y}} A_{\mathrm{s}}+f_{\mathrm{cd}} A_{\mathrm{c}}\left(1+\eta_{\mathrm{co}} t f_{\mathrm{yk}} / d f_{\mathrm{ck}}\right)+f_{\mathrm{ys}} A_{\mathrm{sr}}$

Where $N_{\mathrm{u}}$ represents the plastic axial capacity of the composite section; $\chi$ is the reduction factor; $\eta_{\mathrm{ao}}$ and $\eta_{\mathrm{co}}$ are the factors related to the confinement of concrete; $f_{\text {ck }}$ is the concrete cylinder characteristic compressive strength measured from the compressive test at 28 days; $f_{\mathrm{yk}}$ is the steel characteristic yield strength.

Comparisons between the theoretical predicted values form the test results and the above CFST design specifications are shown in Table.5. American ANSI/AISC 360-16(2016) and Japan AIJ-CFT(1997) underestimate the strength of bond-slip damaged specimens under axial compression, and Chinese GB50936-2014 is a little conservative. The average difference between the test data and the predicted values by the Eurocode 4 (2004) is 1.063, and the mean square error is 0.004, which indicates that the Eurocode 4 (2004) has a high precision. Therefore, it's recommended to adopt the Eurocode 4 (2004) to estimate the ultimate bearing capacity of bond-slip damaged specimens under axial compression

\section{Conclusions}

Six bond-slip damaged specimens and two undamaged specimens are designed and tested in this study. The influences of the diameter-thickness ratio, the expansion ratio and bond-slip damage on the bearing capacity, longitudinal displacement, stiffness and strain of specimens are analyzed and discussed. The bearing capacity of bond-slip damaged specimens is evaluated by the current CFST specifications. The main conclusions can be drawn as follows.

(1) The failure process of undamaged specimens presents three stages as elastic, elastoplastic, and plastic stages. An additional hardening stage can be found in the bond-slip damaged specimens. The failure modes of both bond-slip damaged specimens and undamaged specimen are outward deformation.

(2) The ultimate strength of bond-slip damaged specimens would be decreased by increasing the diameter-thickness ratio. Contrarily, the increase of the expansion ratio would bring benefits to bond-slip damaged specimens. The bond-slip damage has a little influence on the ultimate strength.

(3) The initial damage reduces the member stiffness. The ultimate displacement of bond-slip damaged specimens is larger than that of the undamaged specimen. The increase of the diameter-thickness ratio decreases the ultimate displacement of bond-slip damaged specimens, while the effect of expansion ratio on the ultimate displacement of bond-slip damaged specimens is not significant.

(4) The increase in the diameter-thickness ratio would weaken the confine effects on the inner concrete, which reduces the stiffness of the bond-slip damaged specimens and aggravates the stiffness degradation. The early stiffness of undamaged specimen is larger than that of bond-slip damaged specimens. With the deformation increasing, the stiffness of the two series specimens become comparable.

(5) The specimens with the large expansion ratio or the small diameter-thickness ratio have superior strain capacity.

(6) The accuracy of the CFST design specifications for estimating the strength of the bond-slip damaged specimens is evaluated. The comparisons illustrate the method in Eurocode 4 (2004) can provide the most coherent results for bond-slip damaged specimens than other specifications.

\section{Acknowledgements}

This study was funded by the National Natural Science Foundation of China (No. 51578001, 51878002, 51608003, and 51008001), Key Research and Development Plan of Anhui Province (No. 1704a0802131), and the Outstanding Young Talent Support Program of Anhui Province (No. gxyqZD2016072).

\section{References}

[1] Jiang Y., Ling T.C., Shi C.J. and Pan S.Y., "Characteristics of steel slags and their use in cement and concrete-a review", Resources Conservation and Recycling, 136, 187-197, 2018.

[2] Mayes W.M., Younger P.L. and Aumônier J., "Hydrogeochemistry of alkaline steel slag leachates in the uk", Water Air and Soil Pollution, 195(1-4), 35-50, 2008.

[3] Roslan N.H., Ismail M., Abdulmajid Z., Ghoreishiamiri S. and Muhammad B., "Performance of steel slag and steel sludge in concrete", Construction and Building Materials, 104, 16-24, 2016.

[4] Saxena S. and Tembhurkar A.R., "Impact of use of steel slag as coarse aggregate and wastewater on fresh and hardened properties of concrete", Construction and Building Materials, 165, 126-137, 2018

[5] Han F. and Zhang Z., "Properties of 5-year-old concrete containing steel slag powder", Powder Technology, 334, 27-35, 2018.

[6] Santamaría A., Orbe A. and José JTS., "A study on the durability of structural concrete incorporating electric steelmaking slags", Construction and Building Materials, 161 94-111, 2018.

[7] Wang Q., Wang D. and Zhuang S., "The soundness of steel slag with different free $\mathrm{CaO}$ and MgO contents", Construction and Building Materials, 151, 138-146, 2017.

[8] Shanahan N. and Markandeya A., "Influence of slag composition on cracking potential of slag-portland cement concrete", Construction and Building Materials, 164, 820-829, 2018.

[9] Pang B., Zhou Z. and Xu H., "Utilization of carbonated and granulated steel slag aggregate in concrete", Construction and Building Materials, 84, 454-467, 2015.

[10] Liu J. and Wang D., "Influence of steel slag-silica fume composite mineral admixture on the properties of concrete", Powder Technology, 320, 230-238, 2017.

[11] Han L.H., Li W. and Bjorhovde R., "Developments and advanced applications of concrete-filled steel tubular (CFST) structures: members", Journal of Constructional Steel Research, 100, 211-228, 2014

[12] Shi Y.L., Wang Y.W. and Wang W.D., "Analytical behavior of concrete-filled steel tubular stub column with interal steel reinforced under axial compression", Earthquake Resistant 
Engineering \& Retrofitting,chain, 2013.

[13] Chen J., Wang J. and Li W., "Experimental behaviour of reinforced concrete-filled steel tubes under eccentric tension", Journal of Constructional Steel Research, 136, 91-100, 2017.

[14] Zhou T., Jia Y., Xu M., Wang X. and Chen Z., "Experimental study on the seismic performance of L-shaped column composed of concrete-filled steel tubes frame structures", Journal of Constructional Steel Research, 114, 77-88, 2015.

[15] Chen Y., Feng R., Shao Y. and Zhang X., "Bond-slip behaviour of concrete-filled stainless steel circular hollow section tubes" Journal of Constructional Steel Research, 130, 248-263, 2017

[16] Tomii M., "Bond Check for Concrete-Filled Steel Tubular Columns", Composite \& Mixed Construction, ASCE, 2015.

[17] Tao Z., Song T.Y., Uy B. and Han L.H., "Bond behavior in concrete-filled steel tubes", Journal of Constructional Steel Research, 120, 81-93, 2016.

[18] Ferhoune N., "Experimental behaviour of cold-formed steel welded tube filled with concrete made of crushed crystallized slag subjected to eccentric load", Thin-Walled Structures, 80(1), 159-166, 2014.

[19] Zeghiche, N. F. J., Numerical analysis of cold-formed steel welded tube filled with, concrete made of crystallized slag aggregate. International Journal of Applied Electromagnetics \& Mechanics, 16(1), 112, 2014.

[20] Wei J.G., Huang F.Y. and Chen B.C., "Research on the influence of initial stress to ultimate load carrying capacity of concrete filled steel tubular (single tube) arches", Engineering Mechanics, 27(7), 103-112, 2010.

[21] Xiong D.X., Zha X.X., "A numerical investigation on the behaviour of concrete-filled stee tubular columns under initial stresses", Journal of Constructional Steel Research, 63(5), 599-611, 2007

[22] Hu J.L., Yan Q.S., Yu X.L. and Zheng H.B., "Ultimate bearing capacity analysis of concrete filled steel tubular arch considering the initial defects' influence", Advanced Materials Research, 446-449, 1248-1251, 2012.

[23] Standard Test Method for Long-term and Durability of Ordinary Concrete Use of GB/T50082-2009., Architecture and Building Press, Beijing, China, 2009.

[24] Method of Tensile Test at Room Temperature Use of GB/T228-2010., Architecture an Building Press, Beijing, China, 2010.

[25] Technical Code for Concrete Filled Steel Tubular Structures Use of GB50936-2014., the Ministry of housing and urban-rural development of the people's republic of China, Beijing, China, 2014.

[26] Design Method for Concrete Filled Steel Tubular Structures., the Japan institute of architecture, Japan, 1997.

[27] Specification for Structural Steel Buildings (ANSI/AISC-360-16)., Chicago, Illinois, American: AISC Committee, 2016.

[28] Design of Composite Steel and Concrete Structures., European Committee for Standardizaion, European, 2004. 